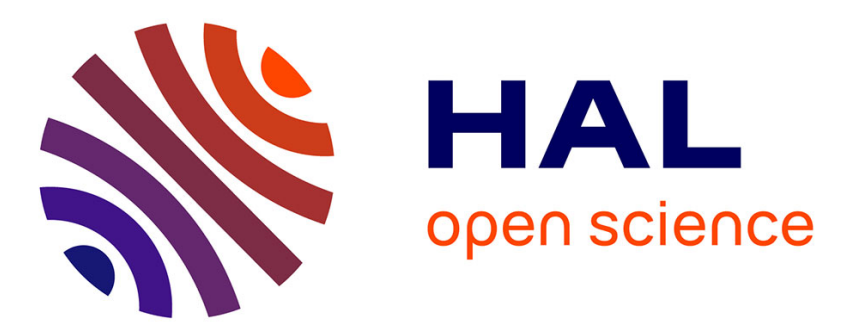

\title{
Surface structures of In-Pd intermetallic compounds. I. Experimental study of In thin films on $\operatorname{Pd}(111)$ and alloy formation
}

\author{
G. M. Mcguirk, J. Ledieu, É. Gaudry, M.-C. De Weerd, V. Fournée
}

\section{To cite this version:}

G. M. Mcguirk, J. Ledieu, É. Gaudry, M.-C. De Weerd, V. Fournée. Surface structures of In-Pd intermetallic compounds. I. Experimental study of In thin films on $\operatorname{Pd}(111)$ and alloy formation. Journal of Chemical Physics, 2014, 141, 084702 (10 p.). 10.1063/1.4892408 . hal-01075808

\section{HAL Id: hal-01075808 \\ https://inria.hal.science/hal-01075808}

Submitted on 20 Oct 2014

HAL is a multi-disciplinary open access archive for the deposit and dissemination of scientific research documents, whether they are published or not. The documents may come from teaching and research institutions in France or abroad, or from public or private research centers.
L'archive ouverte pluridisciplinaire HAL, est destinée au dépôt et à la diffusion de documents scientifiques de niveau recherche, publiés ou non, émanant des établissements d'enseignement et de recherche français ou étrangers, des laboratoires publics ou privés. 


\title{
Surface structures of In-Pd intermetallic compounds. I. Experimental study of In thin films on $\mathrm{Pd}(111)$ and alloy formation
}

\author{
G. M. McGuirk, J. Ledieu, É. Gaudry, M.-C. de Weerd, and V. Fournée \\ Institut Jean Lamour (UMR7198 CNRS-Nancy-Université de Lorraine), Parc de Saurupt, \\ 54011 Nancy Cedex, France
}

(Received 29 April 2014; accepted 5 June 2014; published online 25 August 2014)

\begin{abstract}
A combination of experimental methods was used to study the structure of In thin films deposited on the $\operatorname{Pd}(111)$ surface and the alloying behavior. X-ray photoelectron spectroscopy (XPS), lowenergy electron diffraction (LEED), and scanning tunneling microscopy results indicate that surface alloying takes place at room temperature. Below 2 monolayer equivalents (MLEs), the LEED patterns show the formation of three rotational domains of $\operatorname{InPd}(110)$ of poor structural quality on top of the $\operatorname{Pd}(111)$ substrate. Both core-levels and valence band XPS spectra show that the surface alloy does not yet exhibit the electronic structure characteristic of the 1:1 intermetallic compound under these conditions. Annealing the $1 \mathrm{MLE}$ thin film up to $690 \mathrm{~K}$ yields to a transition from a multilayer InPd near-surface intermetallic phase to a monolayer-like surface alloy exhibiting a well ordered $(\sqrt{3}$ $\times \sqrt{3}) \mathrm{R} 30^{\circ}$ superstructure and an estimated composition close to $\mathrm{In}_{2} \mathrm{Pd}_{3}$. Annealing above $690 \mathrm{~K}$ leads to further In depletion and a $(1 \times 1)$ pattern is recovered. The $(\sqrt{3} \times \sqrt{3}) \mathrm{R} 30^{\circ}$ superstructure is not observed for thicker films. Successive annealing of the 2 MLE thin film leads the progressive disappearance of the InPd diffraction spots till a sharp $(1 \times 1)$ pattern is recovered above $690 \mathrm{~K}$. In the high coverage regime (from 4 to 35 MLE), the formation of three rotational domains of a $b c c-\operatorname{In}_{7} \mathrm{Pd}_{3}$ compound with (110) orientation is observed. This In-rich phase probably grows on top of interfacial $\operatorname{InPd}(110)$ domains and is metastable. It transforms into a pure $\operatorname{InPd}(110)$ near-surface intermetallic phase in a temperature range between 500 and $600 \mathrm{~K}$ depending on the initial coverage. At this stage, the surface alloy exhibits core-level chemical shifts and valence band (VB) spectra identical to those of the 1:1 InPd intermetallic compound and resembling Cu-like density of states. Annealing at higher temperatures yields to a decrease of the In concentration in the near-surface region to about 20 at.\% and a $(1 \times 1)$ LEED pattern is recovered. () 2014 AIP Publishing LLC. [http://dx.doi.org/10.1063/1.4892408]
\end{abstract}

\section{INTRODUCTION}

The catalytic properties of Pd nanoparticles on oxide supports have recently received much attention for hydrogen production in the methanol stream reforming (MSR) process $\left(\mathrm{CH}_{3} \mathrm{OH}+\mathrm{H}_{2} \mathrm{O} \rightarrow \mathrm{CO}_{2}+3 \mathrm{H}_{2}\right) \cdot{ }^{1-6}$ They are considered as potential alternatives to $\mathrm{Cu} / \mathrm{ZnO}$ catalysts used today by industry, offering an improved thermal stability as well as an enhanced activity and selectivity for MSR. ${ }^{3,7,8}$ The high selectivity and activity towards MSR of $\mathrm{Pd} / \mathrm{ZnO}, \mathrm{Pd} / \mathrm{Ga}_{2} \mathrm{O}_{3}$, and $\mathrm{Pd} / \mathrm{In}_{2} \mathrm{O}_{3}$ was attributed to the formation of intermetallic compounds by reduction of the powder catalyst under $\mathrm{H}_{2}$ at high temperature, ${ }^{9,10}$ linked to a shift towards higher binding energies of the Pd d-band upon alloying, making the density of states (DOS) of the alloy resembling that of $\mathrm{Cu}$ metal. ${ }^{11}$ However recent studies have shown that the formation of intermetallic compounds is a necessary but not sufficient condition to gain high selectivity. ${ }^{12,13}$

Many studies have been devoted to the electronic and crystallographic structure of Pd-M $(\mathrm{M}=\mathrm{Zn}, \mathrm{Ga}$, or In) intermetallic phases, which is a prerequisite to understand the chemical reactivity of these prospective catalysts at a microscopic level. Most of them deal with ZnPd intermetallics and a recent review can be found in Ref. 14. The catalytic prop- erties of Pd nanoparticles supported on $\mathrm{ZnO}$ are ascribed to the formation of a stable $\mathrm{ZnPd}$ intermetallic phase with a 1:1 concentration ratio and a tetragonal structure. ${ }^{15,16}$ Experimental studies of the $\mathrm{Zn} / \mathrm{Pd}(111)$ system reported the formation of different surface alloys as a function of temperature and coverages, including a near stoichiometric $\mathrm{ZnPd}$ phase. The latter one is characterized by an apparent $\mathrm{p}(2$ $\times 2$ ) low-energy electron diffraction (LEED) pattern corresponding in fact to 3 rotational domains of a $\mathrm{p}(2 \times 1)$ structure resembling a tetragonal $\mathrm{ZnPd}(111)$ surface with alternating rows of $\mathrm{Pd}$ and $\mathrm{Zn}$ atoms. This near-surface intermetallic phase (NSIP) exhibits the expected $\mathrm{Cu}$-like DOS as well as a rumpling of the outermost surface layer induced by an outward shift of the $\mathrm{Zn}$ atoms and an inward shift of the Pd atoms (into the bulk), ${ }^{16,17}$ associated with a high $\mathrm{CO}_{2}$ selectivity. Upon annealing the film above $550 \mathrm{~K}$, the $\mathrm{Zn}$ concentration in the near-surface region decreases rapidly although an almost stoichiometric monolayer surface alloy remains in the topmost layer. This change in sub-surface chemistry is associated with an inversion of the surface buckling (i.e., Pd-up/Zn-down) and an increased DOS at the Fermi level together with a loss of $\mathrm{CO}_{2}$ selectivity. ${ }^{18}$ Similar trends have also been reported for the $\mathrm{Ga} / \mathrm{Pd}(111)$ system. ${ }^{19}$ These results show that rather subtle modifications of the 
surface alloys can have dramatic effects on their catalytic properties.

In contrast to the $\mathrm{Zn}-\mathrm{Pd}$ and $\mathrm{Ga}-\mathrm{Pd}$ systems, surface alloys in the In-Pd system have received much less attention although $\operatorname{In}_{y} \mathrm{Pd}_{x} / \mathrm{In}_{2} \mathrm{O}_{3}$ are also highly active and selective supported catalysts. ${ }^{20}$ Earlier work by Fink et al. ${ }^{21-23}$ reported compound formation upon In deposition on $\operatorname{Pd}(100)$ surface using perturbed $\gamma \gamma$-angular correlation spectroscopy. A more recent report by Rameshan et al. ${ }^{24}$ found that room temperature deposition of a 4 monolayer equivalents (MLEs) of In on $\mathrm{Pd}$ foil followed by subsequent annealing to $453 \mathrm{~K}$ yields an almost stoichiometric InPd NSIP exhibiting a $\mathrm{Cu}$-like DOS similar to the $\mathrm{ZnPd}$ counterparts. In situ X-ray photoelectron spectroscopy (XPS) under near-ambient pressure demonstrated an almost $100 \% \mathrm{CO}_{2}$ selectivity in a temperature range between 493 and $550 \mathrm{~K}$. A change towards CO selectivity upon annealing above $600 \mathrm{~K}$ is explained by a decrease in the In sub-surface content. This behavior presents some similarities with the $\mathrm{ZnPd}$ system. However little is known about the structure of such near-surface intermetallic InPd phases.

In this work, we investigate the alloying tendency and the structure of In thin films grown on the Pd(111) surface using a combination of experimental methods (XPS, LEED, and STM). We show that different phases form depending on the initial In coverage and annealing temperatures, each possessing different chemical compositions and structural/electronic signatures.

The paper is organized as follows. We first provide experimental details in Sec. II. The results are presented in Sec. III, first for the low coverage regime, then for higher coverages. The main findings are summarized in Sec. IV and compared with the existing literature on related $\mathrm{Pd}-\mathrm{M}(\mathrm{M}=\mathrm{Zn}, \mathrm{Ga}$, or In) systems. We also discuss our experimental results in the light of a joint theoretical study of InPd surface alloys using first-principle calculations. ${ }^{25}$

\section{EXPERIMENT}

A well-polished $\operatorname{Pd}(111)$ sample was placed under ultrahigh vacuum (UHV) conditions with base pressures below $1 \times 10^{-10}$ mbar. An atomically smooth surface free of subsurface carbon contamination was achieved by cycles of $\mathrm{Ar}^{+}$ sputtering at $1 \mathrm{keV}$, followed by annealing to $1173 \mathrm{~K}$, then $\mathrm{O}_{2}$ exposure $\left(\mathrm{P}_{\mathrm{O}_{2}}=10^{-6} \mathrm{mbar}, 15 \mathrm{mn}, 873 \mathrm{~K}\right)$ and a final flash annealing to $1173 \mathrm{~K}$. After multiple cycles, a sharp (1 $\times 1$ ) LEED pattern was obtained and the absence of surface contamination was verified by XPS analysis. Indium was deposited in situ using an e-beam evaporator (EFM3, flux monitored) with the sample held at room temperature in the scanning tunneling microscopy (STM) stage. Thin film growth was investigated from submonolayer coverage up to 35 monolayer equivalent (MLE). Here an MLE is defined as the exposure required to complete one monolayer as observed by STM. The coverage as determined from STM images is found to increase linearly with exposure in the submonolayer regime. The films were annealed at different temperatures measured using a pyrometer with the emissivity set to 0.1 . The temperature was also measured with a K-type thermocouple attached on the manipulator at some distance from the sam- ple. There is a linear relationship between both measurements with an offset of approximately $150^{\circ}$ (thermocouple reading is lower than pyrometer reading).

A polycrystalline InPd sample was also used in the study. An ingot was prepared by induction melting with a nominal composition of $\operatorname{In}_{47} \mathrm{Pd}_{53}$. Then the ingot was annealed in an evacuated quartz glass tube sealed under Ar atmosphere up to $1248 \mathrm{~K}$, maintained at this temperature for $36 \mathrm{~h}$ and then cooled down to room temperature at a rate of $10 \mathrm{~K} / \mathrm{min}$. The crystallographic structure was checked by powder $\mathrm{x}$ ray diffraction (XRD) (space group $P m \overline{3} m, \mathrm{CsCl}$ type, $a=3.23 \AA$ ). The final composition as determined by energy dispersive $\mathrm{X}$-ray analysis was $\mathrm{In}_{47} \mathrm{Pd}_{53}$, consistent with the existence domain of the InPd. ${ }^{26}$ The surface of the polycrystalline sample was prepared under UHV conditions by sputtering and annealing cycles $\left(\mathrm{Ar}^{+}, 1 \mathrm{keV}, 973 \mathrm{~K}\right)$. The surface composition measured by XPS was $\mathrm{In}_{53} \mathrm{Pd}_{47}$, i.e., within the compositional range of the InPd compound.

\section{RESULTS}

\section{A. Low coverage regime $(\theta \leq 2 \mathrm{MLE})$}

\section{Room temperature deposition}

Figure 1 shows a sequence of STM images of the In film on $\operatorname{Pd}(111)$ with increasing coverage up to $\theta \sim 2$ MLE. Small islands of irregular shape are observed on terraces in the early stage of the growth with no preferential nucleation at step edges. With increasing coverage, the number of islands increases, with no obvious coalescence, until completion of the first layer. Then the second layer grows with a similar behavior. The islands exhibit a dendritic shape indicative of a diffusion limited growth process. A similar behavior has been
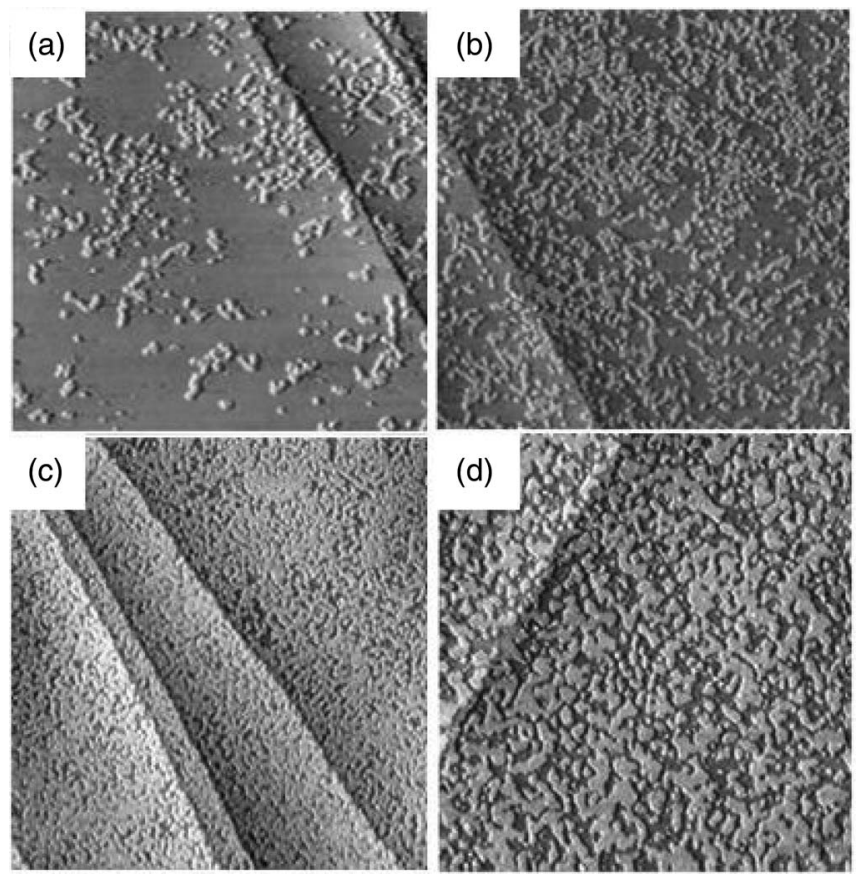

FIG. 1. STM images $\left(200 \times 200 \mathrm{~nm}^{2}\right)$ of the In thin film on $\operatorname{Pd}(111)$ surface for increasing coverage. (a) $0.2 \mathrm{MLE}$ and (b) $0.4 \mathrm{MLE}, V=-2.0 \mathrm{~V}$, $I=0.06 \mathrm{nA}$; (c) 0.8 MLE, $V=+2.0 \mathrm{~V}, I=0.06 \mathrm{nA}$; (d) 1.7 MLE, $V=-1.4 \mathrm{~V}, I=0.10 \mathrm{nA}$ 


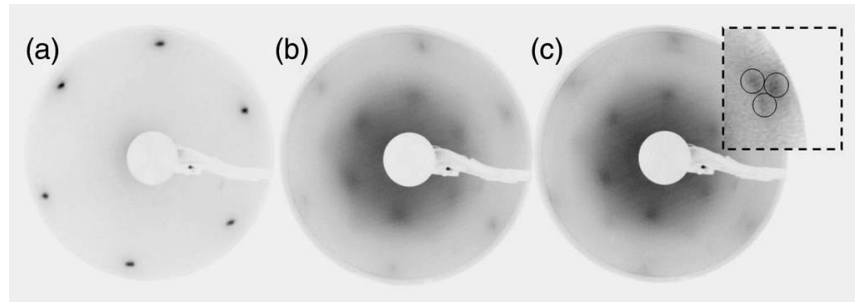

FIG. 2. LEED patterns of (a) the clean Pd(111) surface and after dosing (b) 1 MLE and (c) 2 MLE of In at room temperature. All patterns were recorded at an incident beam energy of $55 \mathrm{eV}$. The dotted rectangle in (c) is a blow-up of one of the outermost diffraction spots showing that they are actually poorly defined triplets.

observed in a study of $\mathrm{Zn}$ thin films on $\mathrm{Pd}(111) .{ }^{27}$ The Pd step height is measured at $2.25 \pm 0.05 \AA$ corresponding to the theoretical $\operatorname{Pd}(111)$ interplanar spacing. The height of the islands is measured at $2.15 \pm 0.05 \AA$.

Figure 2 shows the LEED patterns of the clean $\operatorname{Pd}(111)$ surface (Fig. 2(a)) and after dosing 1 MLE (Fig. 2(b)) and 2 MLE of In (Fig. 2(c)) at room temperature. Already at 1 MLE, a new pattern starts to appear which is slightly improved at 2 MLE coverage. The LEED patterns are quite diffuse in both cases and could be interpreted as either a $(2 \times 2)$ reconstruction or three rotational domains of a $(2 \times 1)$ reconstruction or three rotational domains of another structure resembling a $(2 \times 1)$ reconstruction. However, at 2 MLE, the outer spots appear to be poorly defined triplets (see blow-up in Fig. 2(c)), which rules out the first two hypothesis.

At this stage, the film is not sufficiently ordered to obtain atomically resolved STM images. However, domains can be identified exhibiting atomic rows, rotated by $120^{\circ}$ from each other. The formation of these domains suggests that intermixing already occurs at room temperature. Further evidence for intermixing is provided by the core-level XPS data shown in Fig. 3. The Pd 3d core-level lines of the clean Pd(111) substrate can be fitted with a bulk and a surface contribution as described in Ref. 10. With increasing coverage, an additional peak grows on the high binding energy side, which is further enhanced at high take-off angle of the photoelectrons to increase the surface sensitivity. This peak corresponds to the surface alloy contribution. The position of this additional peak is shifted from the bulk Pd peak by $+0.65 \mathrm{eV}$ at 1 MLE and by $+0.9 \mathrm{eV}$ at 2 MLE. The shift is however smaller than the binding energy shift $(+1.0 \mathrm{eV})$ observed for the InPd polycrystalline reference sample, suggesting that the surface alloy formed at room temperature is different from the stoichiometric compound in this coverage regime. Core-level peak fitting of the $\mathrm{Pd} 3 \mathrm{~d}$ line indicates that the alloy contribution is more symmetric than the Pd bulk peak. The asymmetry of metal core-level line shapes results from intrinsic energy losses through electron-hole pairs excitations across the Fermi level and thus depends on the local density of states (DOS) at the Fermi level $\left(\mathrm{N}\left(\mathrm{E}_{F}\right)\right)^{28,29}$ Therefore the more symmetric line shape of the alloy component indicates a reduced $\mathrm{N}\left(\mathrm{E}_{F}\right)$ in the surface alloy compared to the substrate DOS. Another observation is the disappearance of the shake-up satellite at $+5.9 \mathrm{eV}$ from the $\mathrm{Pd} 3 \mathrm{~d}_{3 / 2}$ upon alloying. The intensity of the shake-up satellite depends on the weight of unoccupied Pd $4 \mathrm{~d}$ character and its position above $\mathrm{E}_{F} \cdot{ }^{30}$ The disappearance

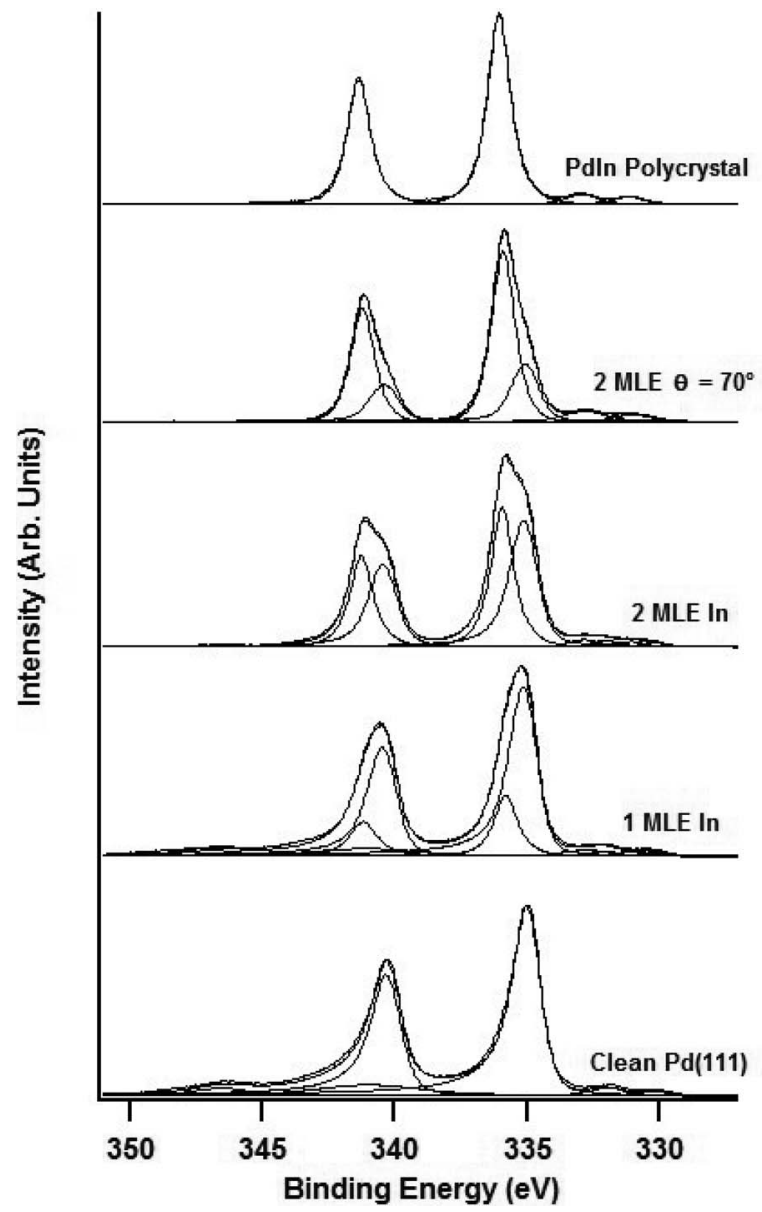

FIG. 3. XPS Pd 3d spectra of the clean Pd(111) surface, after dosing 1 and 2 MLE of In and of the clean polycrystalline InPd sample. All spectra were recorded at $45^{\circ}$ take-off angle except for the second from the top spectrum which was collected at $70^{\circ}$ to enhance surface sensitivity. A clear alloy component can be seen upon In dosing the Pd surface as well as the loss of the asymmetric tail and the disappearance of the shake-up satellites at $346.3 \mathrm{eV}$ binding energy.

of the satellite upon alloying suggests that the Pd d band is being filled and shifted below the Fermi level upon alloying, a feature commonly observed upon intermetallic compound formation. ${ }^{31}$ This is confirmed by XPS valence band measurements shown in Fig. 4. The main peak corresponds to the $\mathrm{Pd} \mathrm{d}$ band which is shifted towards higher binding energies with increasing film thickness to resemble that of the polycrystalline reference sample. However at 2 MLE, the spectral weight within $2 \mathrm{eV}$ below $\mathrm{E}_{F}$ is larger than for the polycrystalline sample. This is probably due to a Pd bulk contribution to the XPS signal in this low coverage regime. The chemical composition of the surface alloy formed at room temperature can be roughly estimated by considering the area of the In $3 \mathrm{~d}$ peak and that of the alloy component of the Pd $3 \mathrm{~d}$ peak, assuming that the In concentration is homogeneous across the alloy thickness. This gives a composition of $\operatorname{In}_{47} \mathrm{Pd}_{53}$ at 1 MLE and $\operatorname{In}_{57} \mathrm{Pd}_{43}$ at 2 MLE.

\section{Annealing 1 MLE thin films}

Upon successive annealing of the 1 MLE thin film up to $690 \mathrm{~K}$, the broad diffraction spots observed at $300 \mathrm{~K}$ 




FIG. 4. Experimental XPS VB spectra of the clean Pd(111) surface, after dosing 1 and 2 MLE of In and of the clean polycrystalline InPd sample. All spectra were recorded at $45^{\circ}$ take-off angle except for the second from the top spectrum which was collected at $70^{\circ}$ to enhance surface sensitivity.

vanish and are replaced by a new well ordered $(\sqrt{3} \times \sqrt{3})$ R30 superstructure (Fig. 5(a)). The corresponding STM image is shown in Fig. 5(b). On large scale images, one observes a two phase mixture, one phase being disordered and covering less than $30 \%$ of the surface area, and an ordered phase with an hexagonal unit cell of dimension $4.75 \AA$ consistent with the $(\sqrt{3} \times \sqrt{3}) \mathrm{R} 30^{\circ}$ superstructure observed by LEED. The STM contrast is not uniform, suggesting either chemical inhomogeneity and/or rumpling and/or structural imperfections. After annealing at $690 \mathrm{~K}$, XPS core-level measurements show a decrease in the In content in the near-surface region. The estimated composition of the surface alloy is equal to $\operatorname{In}_{41} \mathrm{Pd}_{59}$. The uncertainty in this case is rather large because of the difficulty in extracting the Pd $3 \mathrm{~d}$ alloy component out of the total $\mathrm{Pd} 3 \mathrm{~d}$ line. The surface alloy is most likely confined in the topmost surface layers. Above $690 \mathrm{~K}$, the LEED pattern evolves towards a (1x1) pattern. By XPS, the alloy component of the Pd 3d line has almost disappeared while the intensity of the In $3 \mathrm{~d}$ line strongly decreases, indicating that the In atoms have either desorbed or diffused into the bulk.

\section{Annealing 2 MLE thin films}

Upon successive annealing of the 2 MLE thin film, the broad diffraction spots of the reconstruction observed at $300 \mathrm{~K}$ progressively vanish with no evidence of $(\sqrt{3} \times \sqrt{3})$ $\mathrm{R} 30^{\circ}$ ordering in this case. At $690 \pm 10 \mathrm{~K}$, the LEED pattern

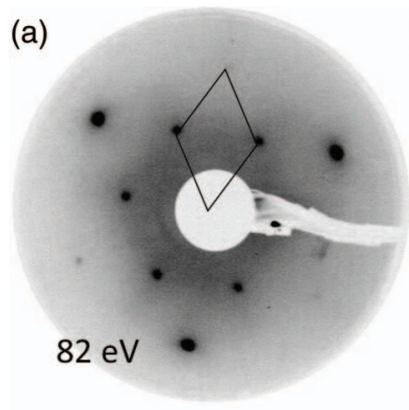

(b)



(c)

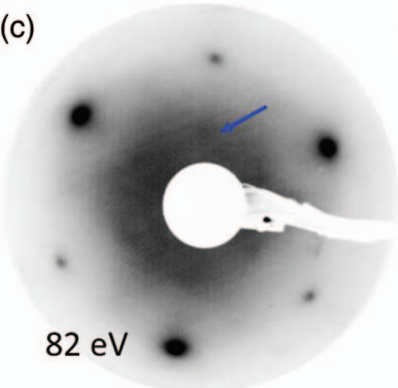

(d)

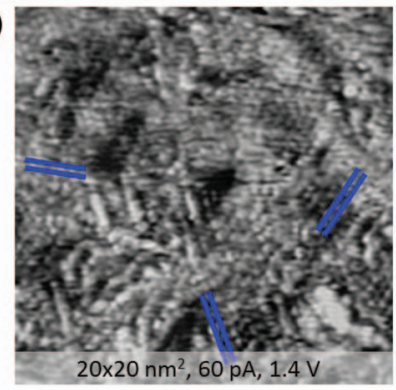

FIG. 5. (a) LEED pattern of the 1 MLE In film on Pd(111) after annealing at $690 \mathrm{~K}$ and (b) corresponding STM image $\left(10 \times 10 \mathrm{~nm}^{2}, \mathrm{~V}=-1.4 \mathrm{~V}\right.$, $\mathrm{I}=0.07 \mathrm{nA})$. (c) LEED pattern of the 2 MLE In film on $\mathrm{Pd}(111)$ after annealing at $690 \mathrm{~K}$ and (d) corresponding STM image $\left(20 \times 20 \mathrm{~nm}^{2}, \mathrm{~V}=+1.4 \mathrm{~V}\right.$, $\mathrm{I}=0.06 \mathrm{nA})$. Atomic rows can be distinguished according to three different orientations as indicated by straight lines in (d). The arrow in (c) points towards one of the diffuse spots arising from the surface alloy.

shown in Fig. 5(c) is obtained where the $(1 \times 1)$ diffraction spots coexist with faint diffuse spots of the InPd surface alloy. An STM image of the corresponding film is shown in Fig. 5(d). The surface alloy is not well ordered but nevertheless domains can be seen presenting atomic rows. The chemical composition of the surface alloy is estimated at $\operatorname{In}_{47} \mathrm{Pd}_{53}$ following the peak fitting procedure described above. Further annealing of the 2 MLE film above $690 \mathrm{~K}$ leads to an even sharper $(1 \times 1)$ LEED pattern and a progressive loss of the In content in the near-surface region.

\section{B. High coverage regime ( $\theta \geq 4$ MLE)}

After deposition of 4 MLE of In on Pd(111) at room temperature, the LEED pattern shown in Fig. 6(a) is observed. It is actually similar to the one obtained after 2 MLE deposition at room temperature except that the diffraction spots are now better resolved. The quality of the LEED pattern can be further improved by annealing the film up to $500 \mathrm{~K}$ as shown in Fig. 6(b). At this stage, the LEED pattern can be described as consisting of three rotational domains of a rectangular structure. The three domains and their relationship with the $\operatorname{Pd}(111)$ substrate are depicted in the LEED pattern in Fig. 6(b). The domains are rotated by $60^{\circ}$ from each other. By calibrating the reciprocal space using the LEED pattern of the clean $\operatorname{Pd}(111)$ surface recorded under the same experimental conditions, it is deduced that the rectangular surface unit cells have dimensions $a=3.28 \pm 0.1 \AA$ and $b=4.64 \pm 0.1 \AA$. These values are close to those of the rectangular unit cell of $\operatorname{InPd}(110)(a=3.25 \AA$ and $b=4.6 \AA)$ and are thus consistent 


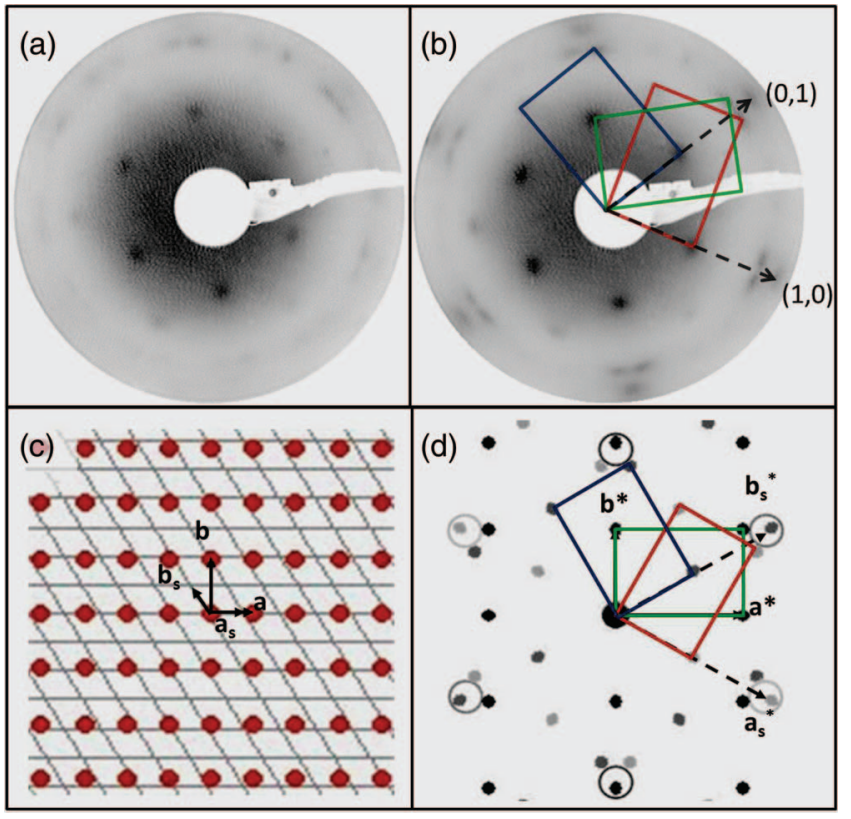

FIG. 6. LEED patterns of (a) the 4 MLE In thin film deposited on $\operatorname{Pd}(111)$ at room temperature and (b) after annealing at $500 \mathrm{~K}$. The two patterns were recorded at an incident beam energy of $50 \mathrm{eV}$. The three rotational domains of the InPd(110) rectangular mesh are superimposed. The dashed arrows correspond to the $\operatorname{Pd}(111)$ lattice vectors. The first order substrate spots are in coincidence with the $(0,2)$ and $(0,-2)$ spots of the $\operatorname{InPd}(110)$ domains. (c) Real space model of a single InPd(110) domain with lattice vectors $(a, b)$ on a $\operatorname{Pd}(111)$ substrate with lattice vector $\left(a_{s}, b_{s}\right)$. (d) Reciprocal space for three rotational domains of $\operatorname{InPd}(110)$ on $\mathrm{Pd}(111)$ substrate. Large circles indicate coincidence reciprocal lattice spots between the surface alloy and the substrate.

with the formation of three rotational domains of $\operatorname{InPd}(110)$ surface alloy on $\mathrm{Pd}(111)$. The orientation of the $\operatorname{InPd}(110)$ domains with respect to the $\mathrm{Pd}(111)$ substrate is determined by the coincidence of the $(0,2)$ and $(0,-2)$ reciprocal lattice spots of the InPd overlayer with the $(0,1)$ and $(0,-1)$ or $(-1,0)$ and $(1,0)$ or $(-1,1)$ and $(1,-1)$ substrate spots, respectively, hence the three rotational domains observed. A schematic of the model is shown in Figs. 6(c) and 6(d), in both real and reciprocal space. Considering the bulk parameters of Pd and InPd compounds, this locking into registry would imply a small lattice expansion of the surface alloy by $3.6 \%$.

At low electron beam energy, additional triplet of spots appear for the same growth conditions; i.e., In deposition of 4 MLE at room temperature. They are slightly better defined after annealing up to $500 \mathrm{~K}$ (Fig. 7(a)) but disappear after annealing at $550 \mathrm{~K}$ (Fig. 7(b)). These triplets of spots do not originate from the $\operatorname{InPd}(110)$ domains themselves but correspond to a structure possessing a larger unit cell. The reciprocal lattice vectors $\left(a_{R}{ }^{*}, b_{R}{ }^{*}\right)$ of this larger structure are shown in the LEED pattern in Fig. 7(a) together with the lattice vector $\left(a^{*}, b^{*}\right)$ of a single $\operatorname{InPd}(110)$ domain. The larger structure corresponds to an oblique surface unit cell having parameters $a_{R}=b_{R}=7.7 \pm 0.1 \AA$ and $\gamma=71^{\circ} \pm 2^{\circ}$ or equivalently to a centred rectangular net with dimensions $a_{R}=9.2 \pm 0.5 \AA$ and $b_{R}=13 \pm 1 \AA$. There are two possibilities to interpret this structure. From a purely geometrical point of view, it can be interpreted as a $c(4 \times 2)$ surface reconstruction of $\operatorname{InPd}(110)$ domains on the $\operatorname{Pd}(111)$ substrate as sketched in the model

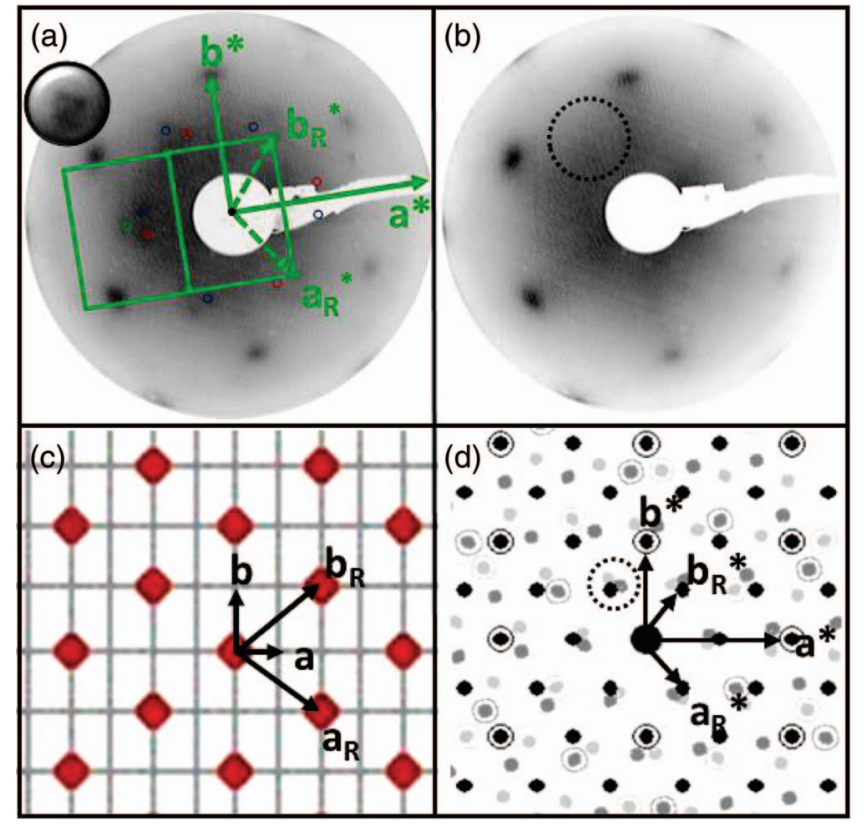

FIG. 7. (a) and (b) LEED patterns recorded at $21 \mathrm{eV}$ beam energy for a 4 MLE In thin film on $\mathrm{Pd}(111)$ after annealing at $500 \mathrm{~K}$ and $550 \mathrm{~K}$, respectively. The additional triplets of spots observed at $500 \mathrm{~K}$ disappear after annealing at $550 \mathrm{~K}$. The reciprocal lattice vectors $\left(\mathrm{a}^{*}, \mathrm{~b}^{*}\right)$ of a single $\operatorname{InPd}(110)$ domain are outlined in (a) as well as those $\left(a_{R}{ }^{*}, b_{R}{ }^{*}\right)$ of the larger structure. The equivalent centered rectangular net is also outlined for a single domain. The first nodes of the two other domains are outlined by empty circles in blue and red, respectively. The circular inset is a magnified view of one triplet of spots. The dotted circle in (b) indicates the position of the missing triplet after annealing at $550 \mathrm{~K}$. (c) Real space model of the "c $(4 \times 2)$ reconstruction" with lattice vector $\left(a_{R}, b_{R}\right)$ on a single domain of $\operatorname{InPd}(110)$. As explained in the text, the " $c(4 \times 2)$ " phase can alternatively be interpreted as $\operatorname{In}_{7} \mathrm{Pd}_{3}$ (110) domains. (d) Reciprocal space model for three rotational domains of $c(4 \times 2)-\operatorname{InPd}(110)$ domains. The dotted circle indicates the triplet of spots observed in LEED patterns.

shown in Figs. 7(c) and 7(d) in both real and reciprocal space. However, the physical origin of such reconstruction is unclear. Considering the fact that its characteristic diffraction spots disappear upon further annealing at $550 \mathrm{~K}$ and that the In concentration in the near-surface region tends to decrease upon annealing as verified by XPS, we can suppose that this structural change is linked to a change in the chemistry of the diffracting overlayer. The In-Pd phase diagram contains several intermetallic compounds. On the In-rich side, one finds the $\mathrm{In}_{7} \mathrm{Pd}_{3}$ compound whose structure is closely related to the $\gamma$-brass structure type. ${ }^{32}$ It has $\operatorname{Im} \overline{3} m$ space group and a lattice parameter $a=9.436 \AA$. The surface unit cell in its (110) plane would thus have dimensions $a=9.436 \AA$ and $b=13.344 \AA$, i.e., close to the values $\left(a_{R}, b_{R}\right)$ measured experimentally. Therefore this additional structure could alternatively be interpreted as three rotational domains of $\operatorname{In}_{7} \mathrm{Pd}_{3}-(110)$ instead of $\mathrm{c}(4 \times 2)-\operatorname{InPd}(110)$ domains.

Atomically resolved STM images of the different structures are shown in Figure 8. The three rotational domains can be clearly observed in Fig. 8(a). The dimensions of the surface unit cell (Fig. 8(b)) are in agreement with the LEED measurements. Such structure is observed either directly after room temperature deposition of $\theta \geq 4$ MLE or after annealing up to $500 \mathrm{~K}$ to improve the structural quality. In these images, 

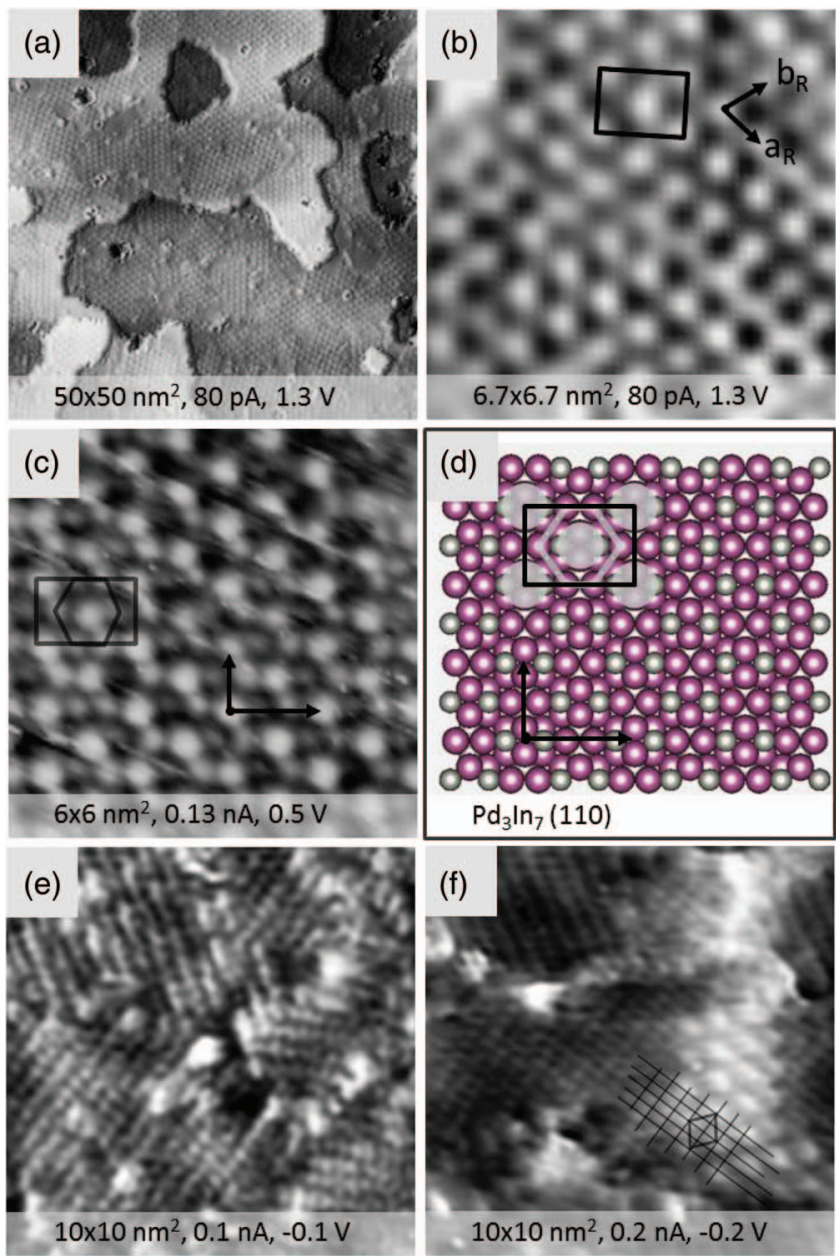

FIG. 8. (a) STM image of the 4 MLE In thin film on Pd(111) after annealing at $500 \mathrm{~K}$ showing multiple domains of the "c $(4 \times 2)$ " structure and (b) its atomic structure. The lattice vectors $\left(\mathrm{a}_{R}, \mathrm{~b}_{R}\right)$ are superimposed on the image, as well as the centered rectangular unit cell. (c) High-resolution STM image of the same structure obtained after room temperature deposition of 16 MLE In on $\mathrm{Pd}(111)$ showing additional contrast within the rectangular unit cell forming an elongated hexagon around each bright dots. (d) Structure model of the $\operatorname{In}_{7} \mathrm{Pd}_{3}$ (110) surface. (e) STM image of a 4 MLE In thin film on $\operatorname{Pd}(111)$ after annealing at $550 \mathrm{~K}$ showing multiple domains of $\operatorname{InPd}(110)$. (f) STM image of the same film as in (e) showing the coexistence of $\operatorname{In}_{7} \mathrm{Pd}_{3}(110)$ and $\operatorname{InPd}(110)$ phases and their orientation relationship.

one can only distinguished bright features at the nodes and at the center of the rectangular unit cell. Therefore it is not possible from such images to discriminate between the two structure models proposed earlier based on LEED patterns, i.e., rotational domains of either $\operatorname{In}_{7} \mathrm{Pd}_{3}(110)$ or $\mathrm{c}(4 \times 2)$ InPd(110). However, in rare cases, a better resolution could be achieved by STM as shown in Fig. 8(c) for a 16 MLE thin film after room temperature deposition. In addition to the bright dots at the nodes and centers of the rectangular mesh, one can distinguish 6 additional features surrounding each bright dot forming an elongated hexagon. The structure model of the (110) surface of the $\operatorname{In}_{7} \mathrm{Pd}_{3}$ intermetallic compound is shown in Fig. 8(d) assuming a bulk termination at dense puckered layer. At the nodes and center of the rectangular mesh, one finds a group of 4 atoms ( $2 \mathrm{Pd}$ and 2 In atoms forming a cross) slightly protruding above the mean position of the plane. Each of these motifs is surrounded by 6 addi- tional In atoms located at about $0.6 \AA$ below. It is reasonable to assume that the groups of 4 protruding atoms are imaged as a bright dots by STM and that the 6 surrounding In atoms appear dimmer because they lie below the mean position of the surface plane. This model presents a good agreement with the experimental observations, supporting the formation of $\mathrm{In}_{7} \mathrm{Pd}_{3}(110)$ domains rather than a $\mathrm{c}(4 \times 2)$ reconstruction of $\operatorname{InPd}(110)$ domains. The film structure changes upon annealing at $550 \mathrm{~K}$ as can be seen in the STM image shown in Fig. 8(e). Now the film structure consists of three rotational domains of the InPd(110) phase in agreement with the LEED results. The dimensions of the surface unit cell measured by STM $(a=3.25 \pm 0.1 \AA$ and $b=4.6 \pm 0.1 \AA)$ are consistent with expected values. It is to be noted that the two structures, $\operatorname{In}_{7} \mathrm{Pd}_{3}(110)$ domains and $\operatorname{InPd}(110)$ domains, are found to coexist at the surface, the former one being the dominant structure after room temperature deposition and annealing up to $500 \mathrm{~K}$ while the latter become the predominant structure after annealing to $550 \mathrm{~K}$. The orientation relationship between the two structures is illustrated in the STM image shown Fig. 8(f), in which a $\operatorname{In}_{7} \mathrm{Pd}_{3}(110)$ domain appears adjacent to a $\operatorname{InPd}(110)$ domain.

To summarize this section on In thin films ( $\theta \geq 4$ MLE) on $\operatorname{Pd}(111)$, surface alloying is observed already after room temperature deposition leading to the formation of three rotational domains of a $\operatorname{In}_{7} \mathrm{Pd}_{3}$ compound with (110) orientation. This In-rich compound may grow directly on top of the $\operatorname{Pd}(111)$ substrate or may develop on top of $\operatorname{InPd}(110)$ domains formed as an interfacial layer in the early stage of the growth. Such near-surface layer is found to be stable up to annealing at $500 \mathrm{~K}$ but transforms into pure $\mathrm{InPd}(110)$ domains upon further annealing to $550 \mathrm{~K}$. This sequence of surface phases has been observed for various coverages, including 4 , 8,16 , and 35 MLE, the transition temperature always being in the range of 500 to $600 \mathrm{~K}$. When the films are further annealed above $690 \mathrm{~K}$, a LEED pattern similar to a $\mathrm{Pd}(1 \times 1)$ pattern is recovered, consistent with what has been already observed for the 2 MLE thin film. Thus the InPd surface alloy is not stable in this temperature range and further In diffusion into the bulk or In desorption must take place. Figure 9 summarizes in a schematic way the different phases formed as a function of coverage and temperature.

Up to now, we have assumed the formation of In-Pd surface alloys based on structural information obtained by LEED and STM. The concentration in the near-surface region has been measured by XPS for the different coverages, before and after annealing in a temperature window of 500 to $600 \mathrm{~K}$. The XPS core-level lines are shown in Figs. 10 and 11 for the different conditions. The composition of the near-surface alloy can be estimated assuming that the surface alloy is chemically homogeneous along the surface normal, a criterion which is most likely not satisfied. We nevertheless use this approximation in order to derive the basic trends in the chemical composition in the near-surface region. Before annealing, the surface alloy composition is In-rich and slowly evolves from $\mathrm{In}_{64} \mathrm{Pd}_{36}$ at $4 \mathrm{MLE}$ to $\mathrm{In}_{79} \mathrm{Pd}_{21}$ at 35 MLE. After annealing, the In concentration in the surface alloy decreases to about $55 \%$, i.e., within the InPd compositional range, for all coverages above $\theta \geq 4$ MLE. A Pd bulk component in the $\mathrm{Pd} 3 \mathrm{~d}$ 


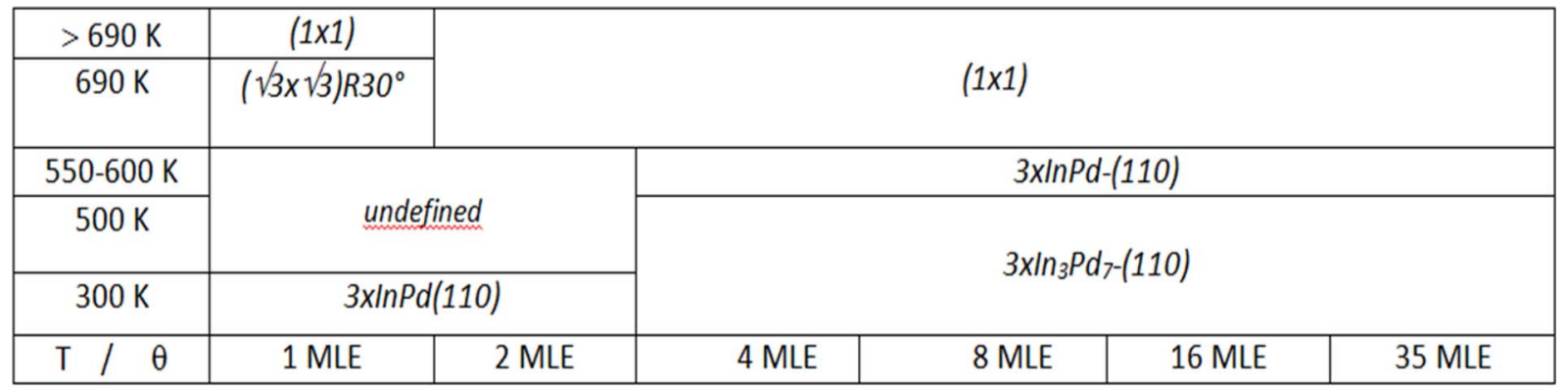

FIG. 9. Schematic summary of the different phases formed as a function of coverage and temperature.

line can still be observed directly after dosing up to 8 MLE, consistent with the probing depth by XPS. However, after annealing the 8 MLE, the Pd bulk component is not detected, which means that the thickness of the surface alloy has increased. The expected surface alloy thickness for a 1:1 stoichiometry at 8 MLE corresponds to 16 atomic planes equivalent to a thickness of $3.7 \mathrm{~nm}$, i.e., larger than the XPS probing depth. Therefore annealing to $500-600 \mathrm{~K}$ is a necessary step to complete the alloy formation. Note that the chemical composition of the near-surface region measured after annealing the films at $500 \mathrm{~K}$ or $600 \mathrm{~K}$ is almost similar within the accuracy of the measurements, although this temperature window corresponds to the transition from the In-rich surface structure $\left(\mathrm{In}_{7} \mathrm{Pd}_{3}\right)$ to the 1:1 InPd compound as determined by LEED

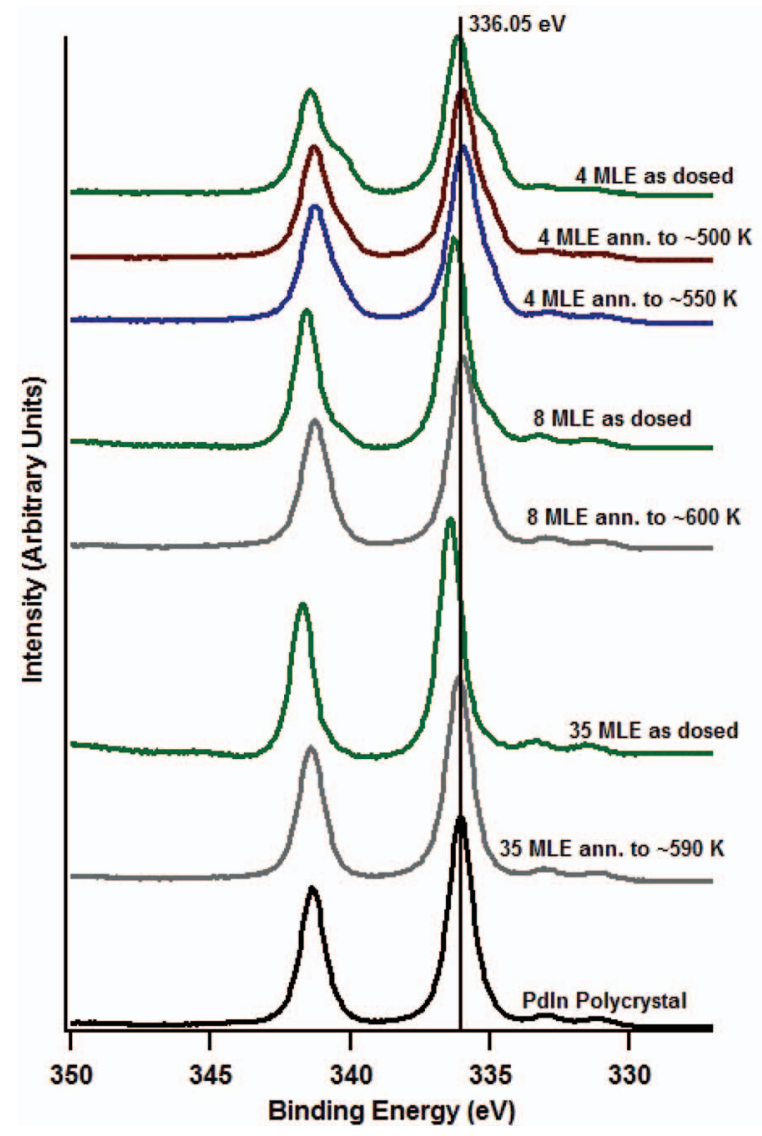

FIG. 10. XPS Pd 3d core-level lines for different film thicknesses, before and after annealing and for the reference InPd polycrystalline sample. and STM. However, for a given coverage, angle-dependent XPS measurements show a small increase of the In content for more surface sensitive conditions $\left(20^{\circ}\right.$ take-off angle instead of $45^{\circ}$ ). These observations are consistent with a gradient of In concentration after room temperature deposition in this coverage regime, decreasing from surface to bulk and being more marked with increasing initial coverage. Probably the InPd compound is first formed at the interface region during growth and then the $\operatorname{In}_{7} \mathrm{Pd}_{3}$ phase is formed on top because the intermixing is not fast enough under these experimental conditions. Upon mild annealing, further diffusion takes place deeper in the bulk allowing the formation of a thicker InPd interface layer. In the temperature range $500-600 \mathrm{~K}$, the $\mathrm{In}_{7} \mathrm{Pd}_{3}$ surface alloy should disappear to leave

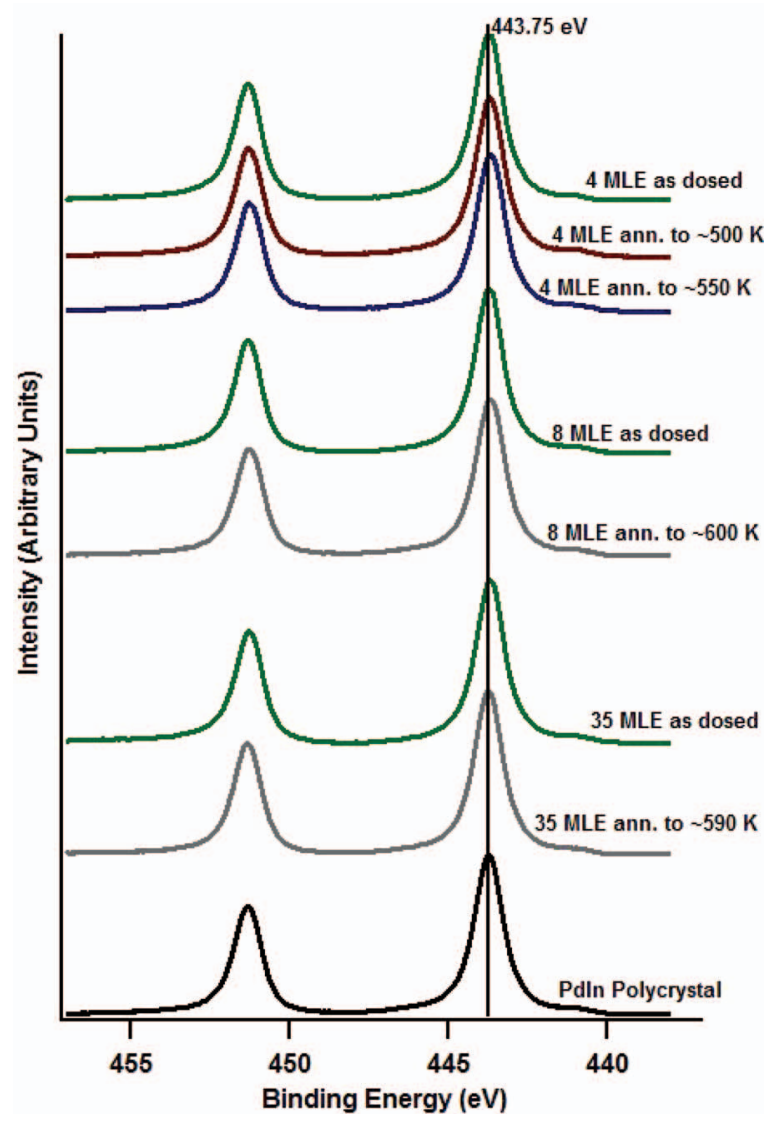

FIG. 11. XPS In 3d core-level lines for different film thicknesses, before and after annealing and for the reference InPd polycrystalline sample. 
TABLE I. Main characteristics of the XPS core-level spectra measured on the reference InPd polycrystalline sample.

\begin{tabular}{lrrrr}
\hline \hline & In $3 d_{3 / 2}$ & In $3 d_{5 / 2}$ & ${\operatorname{Pd~} 3 d_{3 / 2}}$ & ${\operatorname{Pd~} 3 d_{5 / 2}}$ \\
\hline Position $(\mathrm{eV})$ & 451.30 & 443.77 & 341.35 & 336.05 \\
FWHM $(\mathrm{eV})$ & 0.97 & 1.01 & 1.01 & 1.00 \\
\hline \hline
\end{tabular}

a single phase InPd surface alloy. This scenario is consistent with all presented observations. Note that due to the fact that such surface phase transformations are linked to diffusion and intermixing, the exact conditions under which a phase appears should not only depend on initial coverage and annealing temperature but also on the time elapsed between the deposition and the experimental observation.

As observed in Figs. 10 and 11, there is a systematic shift of the Pd $3 \mathrm{~d}$ lines towards lower binding energy upon annealing the films while the In $3 \mathrm{~d}$ line appears mostly at the same binding energy, independently of the conditions shown. We mention however the In $3 \mathrm{~d}_{5 / 2}$ core-level line shifts to $443.5 \mathrm{eV}$ for higher annealing temperature $(690 \mathrm{~K}$, not shown in Fig. 11), associated with a decrease of the In content. The final line shape and binding energies of $\mathrm{Pd} 3 \mathrm{~d}$ and In $3 \mathrm{~d}$ corelevels of the surface alloys after $500-600 \mathrm{~K}$ annealing are in good agreement with those measured for the polycrystalline reference samples $( \pm 0.05 \mathrm{eV})$. The main characteristics of the lines are provided in Table I. The XPS valence band spectra recorded for the same conditions are shown in Fig. 12. The

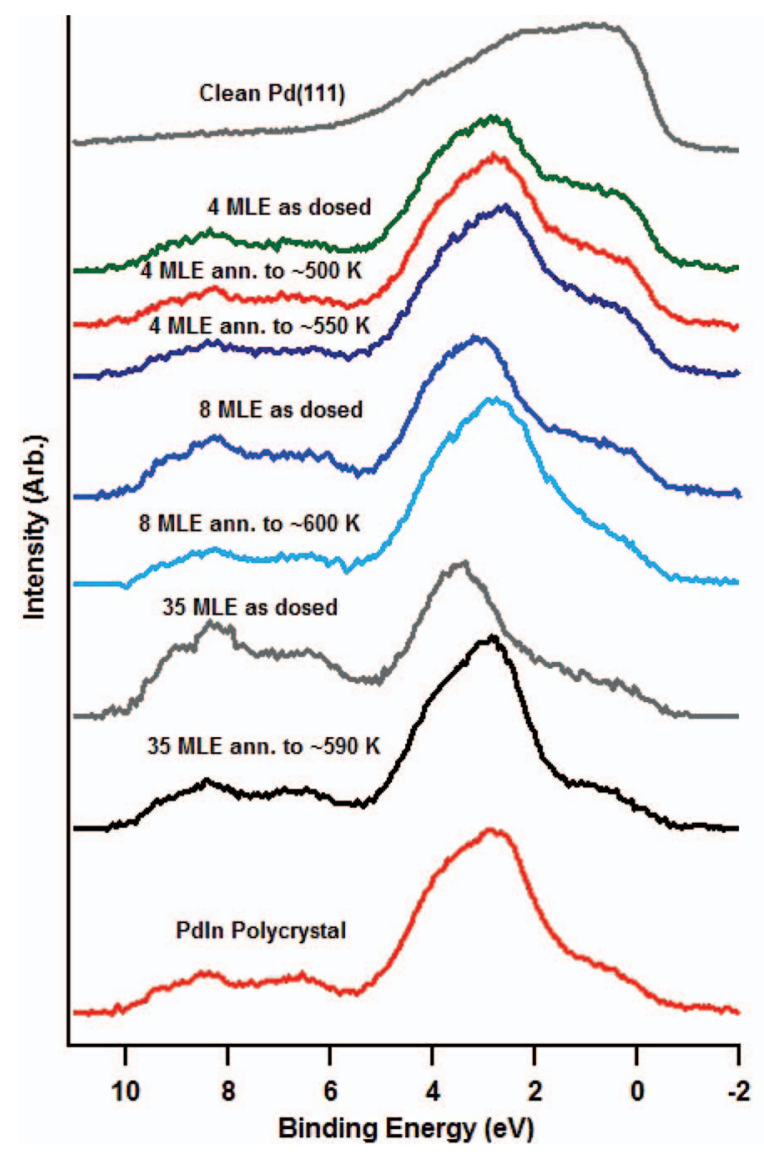

FIG. 12. XPS valence band data showed filling of Pd $4 \mathrm{~d}$ bands to a Cu-like state upon dosing and annealing $\operatorname{In} / \operatorname{Pd}(111)$ films. broad main peak at approximately 2 to $4 \mathrm{eV}$ below $\mathrm{E}_{F}$ arises from the Pd d band of the surface alloy and is being increasingly shifted to higher binding energies with increasing coverage after room temperature deposition. The spectral weight between $2 \mathrm{eV}$ and $\mathrm{E}_{F}$ can be due to some Pd d states contribution of the InPd compound which has some sizable DOS in this energy range (see Ref. 25) as well as some additional contribution from d states of bulk Pd at low enough coverages. Upon annealing, the position of the main Pd $\mathrm{d}$ band shifts back to that measured in the reference polycrystalline sample. Simultaneously, the relative spectral weight within $2 \mathrm{eV}$ below $\mathrm{E}_{F}$ decreases, consistent with an increase in the surface alloy thickness and thus a reduced Pd bulk contribution. The valence band spectra of the annealed films and of the polycrystal agree well and are resembling a "Cu-like" DOS expected for catalytic properties. However, the calculated DOS of the InPd compound shows significant difference with that of bulk $\mathrm{Cu}$ in the energy range of $1.5 \mathrm{eV}$ to $\mathrm{E}_{F}$, because of significant $\mathrm{d}$ states contribution in the intermetallic phase. This is similar to the cases of $\mathrm{ZnPd}$ and $\mathrm{GaPd}$ compounds. ${ }^{33,34}$

\section{DISCUSSION AND CONCLUSIONS}

The experimental results indicate that surface alloying takes place at room temperature upon In dosing on the $\operatorname{Pd}(111)$ surface. This agrees with the theoretical prediction of a negative mixing enthalpy for the $\operatorname{In}_{x} \mathrm{Pd}_{1-x}$ solid solution in the dilute In limit reported in Ref. 25. In the low coverage regime $(\theta \leq 2$ MLE), the LEED patterns are consistent with the formation of three rotational domains of $\operatorname{InPd}(110)$ on top of the Pd(111) substrate. However, the structural quality of the surface alloy is rather low at this stage as evidenced by the diffuse diffraction spots. In addition, both the corelevels and valence band XPS spectra show that the surface alloy does fully exhibit the electronic structure characteristic of the stoichiometric phase under these conditions. Annealing the 1 MLE thin film up to $690 \mathrm{~K}$ yields a well ordered $(\sqrt{3} \times \sqrt{3}) \mathrm{R} 30^{\circ}$ superstructure with hexagonal unit cell dimension of $4.75 \AA$ and an estimated surface alloy composition of $\operatorname{In}_{41} \mathrm{Pd}_{59}$. This observation is consistent with previous reports on a related system, $\mathrm{Sn}$ on $\mathrm{Pd}(111)$, for which a simi$\operatorname{lar}(\sqrt{3} \times \sqrt{3}) \mathrm{R} 30^{\circ}$ phase was identified after annealing and ascribed to the formation of a $\mathrm{Pd}_{2} \mathrm{Sn}$ monolayer surface alloy with $f c c$ structure. ${ }^{31,35,36}$ Calculations of segregation energies indicate that an In-doped layer buried in a $\operatorname{Pd}(111)$ substrate is preferentially located at the surface, therefore we expect this surface alloy to be confined in the outermost plane at this stage. ${ }^{25}$ When the film is further annealed above $690 \mathrm{~K}$, the In content in the near-surface region decreases and a $(1 \times 1)$ pattern is recovered in our case.

The $(\sqrt{3} \times \sqrt{3}) \mathrm{R} 30^{\circ}$ superstructure is not observed for thicker films. Successive annealing of the 2 MLE thin film leads the progressive disappearance of the InPd diffraction spots till a sharp $(1 \times 1)$ pattern is recovered above $690 \mathrm{~K}$.

In the high coverage regime (from 4 to 35 MLE), LEED, STM, and XPS results indicate the formation of three rotational domains of a $\operatorname{In}_{7} \mathrm{Pd}_{3}$ compound with (110) orientation. This In-rich phase grows either directly on top of the $\mathrm{Pd}(111)$ substrate or on top of $\operatorname{InPd}(110)$ domains formed as an 
interfacial layer in the early stage of the growth. The nearsurface layer is found to be stable upon annealing up to about $500 \mathrm{~K}$ and transforms into pure $\operatorname{InPd}(110)$ domains in a temperature range comprised between 500 and $600 \mathrm{~K}$ depending on the initial coverage. At this stage, the surface alloy exhibits core-level chemical shifts and VB spectra identical to those of the stoichiometric InPd intermetallic compound. In particular, a "Cu-like" DOS is observed. Annealing at higher temperatures leads to a decrease of the In concentration in the nearsurface region suggesting that the surface alloy is not stable in this temperature range. A $(1 \times 1)$ LEED pattern is recovered at $690 \mathrm{~K}$, together with a Pd-like DOS.

Our results are consistent with the conclusions of a previous XPS study on In-doped Pd foil performed by Rameshan et $a{ }^{24}{ }^{24}$ In this work, a 4 MLE In thin film was deposited on a polycrystalline $\mathrm{Pd}$ substrate and the chemical composition of the NSIP as well as chemical shifts and VB were monitored as a function of the annealing temperature using synchrotron radiation based XPS. A high degree of alloying was also reported at room temperature. Upon successive annealing, the Pd 3d peaks gradually shifted towards lower binding energies associated with a decrease of the In content in the near-surface region and correlated with a transition from a "Cu-like" DOS to a more "Pd-like" (i.e., a shift of the $\mathrm{d}$ band center towards $\mathrm{E}_{F}$ ). By varying the photon source energy (and hence the probing depth), a concentration gradient was highlighted from an In-rich next to the surface to a more In-depleted alloy in deeper layers. The concentration gradient was found to be more pronounced after low temperature annealing, from $\operatorname{In}_{63} \mathrm{Pd}_{37}$ at $0.4 \mathrm{~nm}$ inelastic mean-free path (IMFP) to $\mathrm{In}_{51} \mathrm{Pd}_{49}$ at $1 \mathrm{~nm}$ at $363 \mathrm{~K}$ annealing. These concentration values support our hypothesis that $\mathrm{In}_{7} \mathrm{Pd}_{3}$ phase is formed on top of a 1:1 InPd interface layer. Annealing to $453 \mathrm{~K}$ yielded to a $1: 1 \mathrm{In} / \mathrm{Pd}$ ratio in the near-surface region exhibiting a "Cu-like" DOS and In depth distribution similar to the MSR-selective multilayer $\mathrm{ZnPd}$ counterpart. ${ }^{16}$ The 4 MLE In thin film annealed at $453 \mathrm{~K}$ was therefore used as a model surface to study the catalytic properties of the InPd system. In these experiments, the temperature was measured with a thermocouple directly attached to the sample, thus providing more reliable temperature values than those reported in the present work. Using the gradual shift of the $\mathrm{Pd}$ $3 \mathrm{~d}$ peaks upon annealing as an internal temperature calibration, we determined that the $453 \mathrm{~K}$-annealed state in Ref. 24 corresponds to our 500 to $550 \mathrm{~K}$ annealed state. In Rameshan et al. ${ }^{24}$ the structure of the $1: 1 \mathrm{InPd}$ NSIP was considered as that of a substitutional alloy with progressive replacement of Pd atoms by In within the Pd- $f c c$ lattice with no relationship with bulk intermetallic phases of the In-Pd system. Our STM and LEED results show that the structure of the surface alloys formed on the $\operatorname{Pd}(111)$ substrate under similar conditions actually corresponds to intermetallic phases rather than substitutional alloys, either cubic CsCl-type InPd or $b c c-\operatorname{In}_{7} \mathrm{Pd}_{3}$ depending on the conditions. This conclusion is also consistent with a previous analysis by $\mathrm{X}$-ray diffraction of $\mathrm{In} / \mathrm{Pd}$ multilayer stackings on $\mathrm{SiO}_{2}$ demonstrating the formation of these two compounds induced by room temperature interdiffusion. ${ }^{37}$ The near-surface intermetallic phases are not stable upon annealing at higher temperatures. The
In content decreases to reach a $\mathrm{In} / \mathrm{Pd}$ ratio of about 20:80 and a $(1 \times 1)$ LEED pattern is recovered. This conclusion is again consistent with earlier reports indicating a similar $\mathrm{In} / \mathrm{Pd}$ ratio throughout the near-surface region after annealing the 4 MLE thin film at $673 \mathrm{~K} .{ }^{24}$ Therefore the InPd surface alloys must be considered as metastable phases. This conclusion is consistent with the results of a theoretical study of InPd surface alloys using first-principles calculations demonstrating that In-doped Pd layers on $\mathrm{Pd}(111)$ are energetically more stable for In concentrations lower than 50 at. $\%{ }^{25}$

The formation of metastable phases with a global 1:1 composition is common to the related $\mathrm{Zn} / \mathrm{Pd}(111)^{10,16,18,27,38}$ and $\mathrm{Ga} / \mathrm{Pd}(111)^{19}$ systems. However, the composition changes are more gradual in the cases of $\mathrm{Ga} / \mathrm{Pd}(111)$ and $\operatorname{In} / \operatorname{Pd}(111)$ compared to $\mathrm{Zn} / \mathrm{Pd}(111)$ for which a more pronounced plateau in the surface composition was observed between 400 and $550 \mathrm{~K}$. For $\mathrm{Zn} / \mathrm{Pd}(111)$, the 1:1 plateau correlates with the formation of an ordered $(2 \times 2)$ surface structure corresponding to 3 rotational domains of $\mathrm{ZnPd}(111)-(2$ $\times 1)^{27,39}$ whereas for $\mathrm{Ga} / \mathrm{Pd}(111)$ the surface alloy is disordered in the same temperature range. ${ }^{19}$ The onset temperatures for alloy formation were found to be different for $\mathrm{Ga}$ and $\mathrm{Zn}$ on $\mathrm{Pd}(111)$ (200 $\mathrm{K}$ for the former versus $300 \mathrm{~K}$ for the latter). This was interpreted as a consequence of the larger thermodynamic driving force for $\mathrm{Ga}-\mathrm{Pd}$ compound formation compared to $\mathrm{Zn}-\mathrm{Pd}$ based on the calculated cohesive energies. The onset alloying temperature was not determined in the present study but is lower or equal to $300 \mathrm{~K}$. This is consistent with the cohesive energy calculated for the InPd compound $(-3.57 \mathrm{eV} / \text { atom })^{25}$ which is intermediate between that of PdGa (-3.9 eV/atom $)^{19,40}$ and $\mathrm{ZnPd}(-3.0 \mathrm{eV} /$ atom $){ }^{41}$ Concerning the orientation of the surface alloys, we found that the cubic 1:1 InPd NSIP adopts a (110) orientation with respect to the $\mathrm{Pd}(111)$ substrate whereas the $1: 1$ tetragonal $\mathrm{ZnPd}$ NSIP adopts a (111) orientation. In both cases, it corresponds to stoichiometric layers consisting of alternating atomic rows of $\mathrm{Pd}$ and $\mathrm{In}$ (or $\mathrm{Zn}$ ) metals. Only one type of atomic rows is observed in corresponding STM images. For $\mathrm{Zn} / \mathrm{Pd}(111)$, this feature can be ascribed to an outward shift of the $\mathrm{Zn}$ atoms and an inward shift of the Pd atoms (into the bulk) with respect to the bulk-terminated geometry as demonstrated by DFT calculations. ${ }^{39,41}$ This is consistent with the lower elemental surface energy of $\mathrm{Zn}$ compared to $\mathrm{Pd}$. A similar effect is expected to occur on the InPd surface alloy, as the elemental surface energy of In is also much lower than that of Pd. Such type of surface relaxation can have a significant effect on the surface reactivity and is investigated theoretically in the part II of this article (Ref. 25).

\section{ACKNOWLEDGMENTS}

This work was supported by the ANR CAPRICE 2011INTB 1001-01, the European C-MAC consortium and COST Action CM0904 "Intermetallic compounds as catalyst for steam reforming of methanol (IMC-SRM)."

${ }^{1}$ D. R. Palo, R. A. Dagle, and J. D. Holladay, Chem. Rev. 107, 3992 (2007). ${ }^{2}$ N. Iwasa, S. Masuda, N. Ogawa, and N. Takezawa, Appl. Catal. A 125, 145 (1995) 
${ }^{3}$ N. Iwasa and N. Takezawa, Top. Catal. 22, 215 (2003).

${ }^{4}$ H. Gabasch, A. Knop-Gericke, R. Schlögl, S. Penner, B. Jenewein, K. Hayek, and B. Klötzer, J. Phys. Chem. B 110, 11391 (2006).

${ }^{5}$ S. Liu, K. Takahashi, and M. Ayabe, Catal. Today 87, 247 (2003).

${ }^{6}$ S. Liu, K. Takahashi, K. Uematsu, and M. Ayabe, Appl. Catal. A 277, 265 (2004).

${ }^{7}$ D. L. Trimm and Z. I. Önsan, Catal. Rev. 43, 31 (2001).

${ }^{8}$ N. Takezawa and N. Iwasa, Catal. Today 36, 45 (1997).

${ }^{9}$ H. Lorenz, S. Turner, O. I. Lebedev, G. V. Tendeloo, B. Klötzer, C. Rameshan, K. Pfaller, and S. Penner, Appl. Catal. A 374, 180 (2010).

${ }^{10}$ A. Bayer, K. Flechtner, R. Denecke, H. Steinruck, K. Neyman, and N. Rosch, Surf. Sci. 600, 78 (2006).

${ }^{11}$ K. Nozawa, N. Endo, S. Kameoka, A. P. Tsai, and Y. Ishii, J. Phys. Soc. Jpn. 80, 064801 (2011).

${ }^{12}$ M. Friedrich, D. Teschner, A. Knop-Gericke, and M. Armbrüster, J. Catal. 285, 41 (2012)

${ }^{13}$ M. Friedrich, S. Penner, M. Heggen, and M. Armbrüster, Angew. Chem. Int. Ed. 52, 4389 (2013)

${ }^{14}$ M. Armbrüster, M. Behrens, K. Fttinger, M. Friedrich, É. Gaudry, S. K. Matam, and H. R. Sharma, Catal. Rev. Sci. Eng. 55, 289 (2013).

${ }^{15}$ S. Penner, B. Jenewein, H. Gabasch, B. Klötzer, D. Wang, A. KnopGericke, R. Schlögl, and K. Hayek, J. Catal. 241, 14 (2006).

${ }^{16}$ C. Rameshan, C. Weilach, W. Stadlmayr, S. Penner, H. Lorenz, M. Havecker, R. Blume, T. Rocha, D. Teschner, A. Knop-Gericke, R. Schlögl, D. Zemlyanov, N. Memmel, G. Rupprechter, and B. Klötzer, J. Catal. 276, 101 (2010).

${ }^{17}$ C. Rameshan, W. Stadlmayr, C. Weilach, S. Penner, H. Lorenz, M. Hävecker, R. Blume, T. Rocha, D. Teschner, A. Knop-Gericke, R. Schlögl, N. Memmel, D. Zemlyanov, G. Rupprechter, and B. Klötzer, Angew. Chem. Int. Ed. 49, 3224 (2010).

${ }^{18}$ W. Stadlmayr, C. Rameshan, C. Weilach, H. Lorenz, M. Haevecker, R. Blume, T. Rocha, D. Teschner, A. Knop-Gericke, D. Zemlyanov, S. Penner, R. Schlögl, G. Rupprechter, B. Klötzer, and N. Memmel, J. Phys. Chem. C 114, 10850 (2010).

${ }^{19}$ W. Stadlmayr, V. Huber, S. Penner, B. Klötzer, and N. Memmel, J. Phys. Chem. C 117, 19558 (2013).

${ }^{20}$ N. Iwasa, T. Mayanagi, N. Ogawa, K. Sakata, and N. Takezawa, Catal. Lett. 54, 119 (1998).

${ }^{21}$ R. Fink, B. U. Runge, K. Jacobs, G. Krausch, B. Luckscheiter, R. Platzer, U. Wöhrmann, and G. Schatz, Hyperfine Interact. 78, 309 (1993).
${ }^{22}$ R. Fink, T. Koch, G. Krausch, J. Marien, A. Plewnia, B.-U. Runge, G. Schatz, A. Siber, and P. Ziemann, Phys. Rev. B 47, 10048 (1993).

${ }^{23}$ R. Fink, B. U. Runge, K. Jacobs, G. Krausch, J. Lohmuller, B. Luckscheiter, U. Wohrmann, and G. Schatz, J. Phys. Condens. Matter 5, 3837 (1993).

${ }^{24}$ C. Rameshan, H. Lorenz, L. Mayr, S. Penner, D. Zemlyanov, R. Arrigo, M. Haevecker, R. Blume, A. Knop-Gericke, R. Schlögl, and B. Klötzer, J. Catal. 295, 186 (2012).

${ }^{25}$ É. Gaudry, G. M. McGuirk, J. Ledieu, and V. Fournée, J. Chem. Phys. 141, 084703 (2014).

${ }^{26} \mathrm{H}$. Okamoto, J. Phase Equilib. 24, 481 (2003).

${ }^{27}$ G. Weirum, M. Kratzer, H. P. Koch, A. Tamtoegl, J. Killmann, I. Bako, A. Winkler, S. Surnev, F. P. Netzer, and R. Schennach, J. Phys. Chem. C 113, 9788 (2009).

${ }^{28}$ G. D. Mahan, Phys. Rev. 163, 612 (1967).

${ }^{29}$ G. K. Wertheim and P. H. Citrin, Photoemission in Solids I (SpringerVerlag, 1978).

${ }^{30}$ F. U. Hillebrecht, J. C. Fuggle, P. A. Bennett, and Z. Zonierek, Phys. Rev. B 27, 2179 (1983).

${ }^{31}$ A. Pancotti, A. de Siervo, M. Carazzolle, R. Landers, and G. Kleiman, J. Electron Spectrosc. Relat. Phenom. 156-158, 307 (2007).

${ }^{32}$ H. Flandorfer, J. Alloys Compd. 336, 176 (2002).

${ }^{33}$ S. A. Villaseca, D. Kandaskolov, É. Gaudry, and M. Armbrüster, Z. Anorg. Allg. Chem. 640, 753 (2014).

${ }^{34}$ K. Kovnir, M. Armbrüster, D. Teschner, T. Venkov, F. Jentoft, A. KnopGericke, Y. Grin, and R. Schlögl, Sci. Technol. Adv. Mater. 8, 420 (2007).

${ }^{35}$ A. F. Lee, C. J. Baddeley, M. S. Tikhov, and R. M. Lambert, Surf. Sci. 373, 195 (1997)

${ }^{36}$ M. Carazzolle, G. Kleiman, R. Landers, A. Pancotti, A. de Siervo, and E. Soares, J. Mol. Catal. A: Chem. 281, 9 (2008).

${ }^{37}$ A. Wronkowska, A. Wronkowski, A. Bukaluk, M. Trzciński, and K. Okulewicz, Appl. Surf. Sci. 253, 3367 (2007).

${ }^{38}$ W. Stadlmayr, S. Penner, B. Klötzer, and N. Memmel, Surf. Sci. 603, 251 (2009)

${ }^{39}$ H. Koch, I. Bako, and R. Schennach, Surf. Sci. 604, 596 (2010).

${ }^{40}$ J. Prinz, R. Gaspari, C. A. Pignedoli, J. Vogt, P. Gille, M. Armbrüster, H. Brune, O. Gröning, and R. Widmer, Angew. Chem., Int. Ed. 51, 9339 (2012).

${ }^{41}$ Z.-X. Chen, K. Neyman, A. Gordienko, and N. Rösch, Phys. Rev. B 68, 075417 (2003). 